
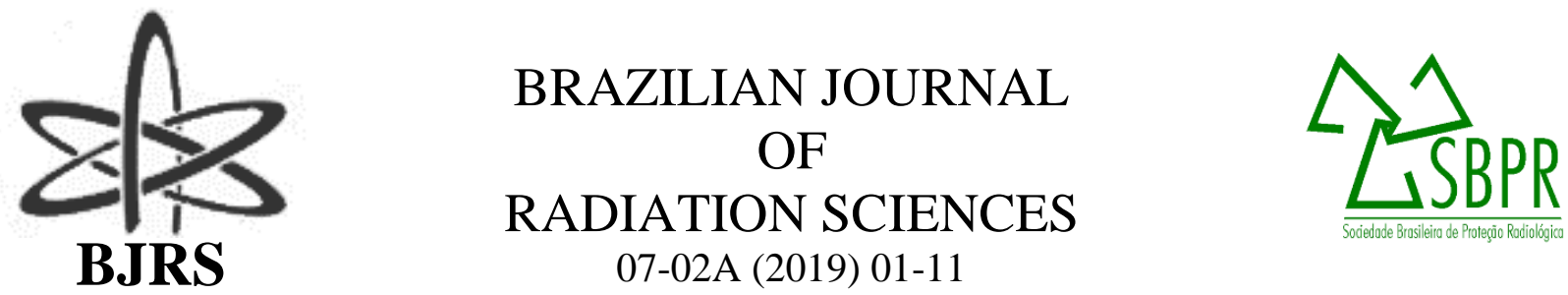

\title{
Establishment of cementation parameters of dried waste from evaporation coming from NPP operation
}

\author{
Érica Rodrigues de Faria ${ }^{1}$, Clédola Cássia Oliveira de Tello ${ }^{1}$, Bruna Silveira Costa ${ }^{2}$ \\ ${ }^{1}$ Centro de Desenvolvimento da Tecnologia Nuclear \\ ${ }^{2}$ Universidade Federal de Minas Gerais \\ e-mail: ericarodriguesfaria@gmail.com
}

\begin{abstract}
The radioactive wastes generated in Brazil are treated and sent to initial and intermediate storages. The "Project RBMN" proposes the implantation of the Brazilian repository to receive and permanently dispose the low and intermediate level radioactive wastes. The evaporator concentrate (EC) is one of liquid wastes generated in a Nuclear Power Plant operation and usually it is cemented directly inside the packing. The aim of this work was to increase the amount of the incorporated waste in each package, using the drying process before the cementation, consequently reducing the volume of the disposed waste. Drying and cementation parameters were established, aiming to obtain cemented waste products that comply with the requirements of Brazilian standard "Acceptance Criteria for Disposal of Low and Intermediate Radioactive Wastes (LIRW)". The evaporator concentrate (EC) was dried in lab oven and the dried EC was cemented, varying the amount of cement, dry waste and water. In the preliminary studies, it was incorporated 5\% of dried EC in the product, using water/cement ratio of 0.27 . This result suggests the possibility of continuing the research to improve the EC incorporation.
\end{abstract}

Keywords: waste, dried process, cementation, acceptance criteria, repository.

ISSN: 2319-0612

Accepted: 2018-12-12 


\section{INTRODUCTION}

The production of energy by a Nuclear Power Plant (NPP) has advantages over other types of sources. The biggest one is an environmental advantage: it does not use fossil fuels, preventing the gas release, into the atmosphere, which is responsible for increasing global warming and formation of other toxic products. In addition, nuclear power plants occupy relatively small areas, can be installed near the consumers, and do not depend on climatic factors. The fuel, uranium, is a low-cost material, since the global reserves are large and there is no risk of lack of provision on the middleterm [1].

In the world, there are 441 power reactors, 63\% are PWR (Pressurized Water Reactor) type, including the Brazilian ones: Angra 1 and Angra 2 (in operation), and Angra 3 (under construction). These NPPs are in the site of Central Nuclear Almirante Álvaro Alberto - CNAAA [2]. To control the fission nuclear reactivity, avoiding uncontrolled chain reactions, boron is used as moderator [3].

Some liquid wastes generated in a NPP are treated by evaporation which involves the distillation of the solvent present in the waste, leaving a small volume of residue containing radionuclides and inactive salts. Evaporation present two advantages: a high volume reduction and a good decontamination factor (DF) for wastes without volatile nuclides from $10^{4}$ to $10^{6}[4,5,6]$.

Currently, the wastes from CNAAA are treated and stored in initial storage facilities. The solidification of the evaporator concentrate is its incorporation in a matrix, which can be cement (Angra 1) or bitumen (Angra 2) [7].

The cement is a material widely used in low and medium activity wastes, due to the accessibility, low cost, simplicity in the process and it is carried out at room temperature [8]. It also present the advantage of its compatibility with water, and the high density and mechanical strength of the cemented product. Nevertheless, an issue of the cementation is the increase of the final volume. In order to cross this barrier, the evaporator concentrate should be reduced before cementation. An option for reducing the volume of waste is to dry it $[9,10,11]$. 
Toscano [9] investigated the feasibility of drying to reduce the volume of the evaporator concentrate. He studied the waste characteristics, different equipments and drying processes. In addition, he established the main process parameters.

The standard CNEN NN 8.01 - Management of Low and Intermediate Waste Levels - establishes the classification of radioactive waste and its management from the segregation until final disposal, ensuring that the lowest waste volume comes from nuclear activities [12]. According to the standard CNEN NN 6.09 - Acceptance Criteria for Disposal of Low and Intermediate Radiation Level Radioactive Waste (LIRW) - the liquid waste must be homogeneously incorporated in a matrix with a minimum of segregated material, producing a monolithic product in a packaging approved by Brazilian National Nuclear Energy Commission - CNEN. These standards define the necessary criteria for a secure and safely disposal of the radioactive low and intermediate radiation level wastes [13].

The Brazilian Repository, whose project is in progress, will receive and store the treated low and intermediate level radioactive wastes [14]. Its concept is a multi-barrier, repository as packaging, filling material, concrete barriers and near field (Figure 1) [15].

Figure 1: Model repository barriers.

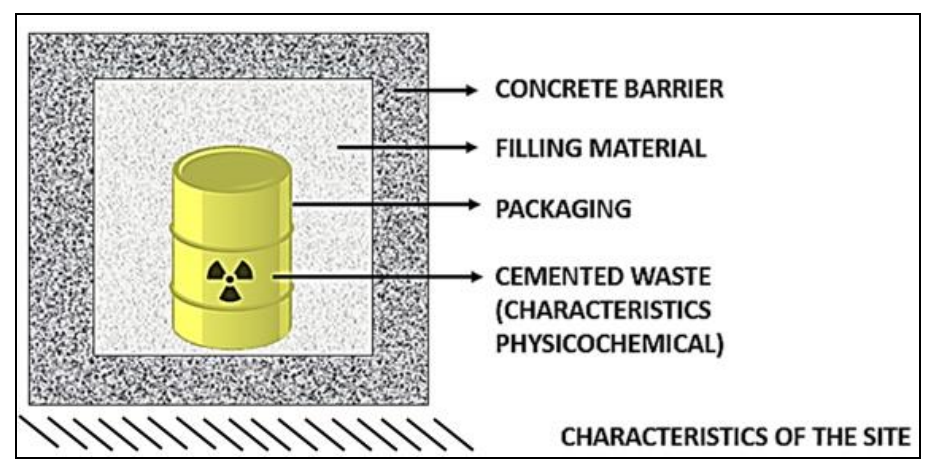

Source: Adapted from [15]

In order to better comply with the requirements, experiments are being carried out with evaporator concentrate. The objective was to define the best route for the drying process and subsequently cementation. In this way the cemented product could has the maximum waste amount, maintaining its quality. The tests described in this work were preliminary and are described as the initial procedures. 


\section{MATERIALS AND METHODS}

The methodology was developed according to the flowchart presented in Figure 2.

Figure 2: Methodology flowchart.

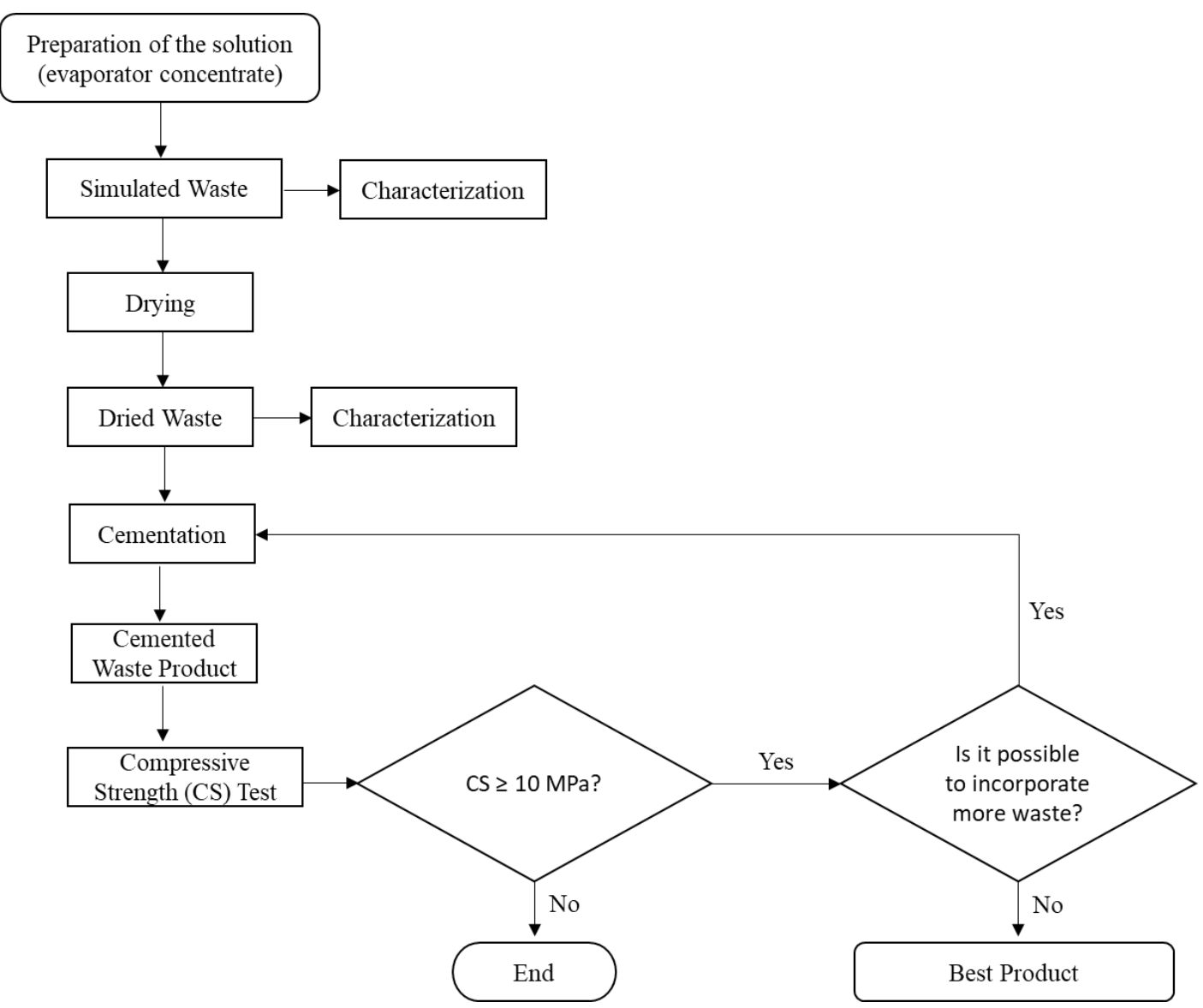

For the study, a solution of the waste was prepared to simulate the PWR evaporator concentrate (EC) as presented in Table 1 . This simulated waste was kept in $80{ }^{\circ} \mathrm{C}$ to avoid the boron precipitation. In this waste, the density and the $\mathrm{pH}$ were determined using a pycnometer and an electronic pHmeter, respectively.

Table 1: Reagents used to prepare $3 \mathrm{~L}$ of simulated waste. 


\begin{tabular}{lclc}
\hline \multicolumn{1}{c}{ Reagents } & Quantity & \multicolumn{1}{c}{ Reagents } & Quantity \\
\hline $\mathbf{M g C l}_{2}$ & $0.082 \mathrm{~g}$ & $\mathbf{C a}\left(\mathbf{N O}_{3}\right)_{2}$ & $1.591 \mathrm{~g}$ \\
$\mathbf{S i O}_{2}$ & $0.089 \mathrm{~g}$ & $\mathbf{N a O H}(\mathbf{1 . 0 2 3 N})$ & $39.50 \mathrm{~mL}$ \\
$\mathbf{N a C l}$ & $0.374 \mathrm{~g}$ & $\mathbf{H}_{3} \mathbf{B O}$ & $369.0 \mathrm{~g}$ \\
$\mathbf{A l}_{2} \mathbf{O}_{3}$ & $0.800 \mathrm{~g}$ & & \\
\hline
\end{tabular}

This solution was characterized before and after the drying process. The measured parameters were the density, the $\mathrm{pH}$ and the boron amount.

\subsection{Drying}

As presented by Toscano [9], there are many drying processes and different equipment can be used. For this research, the evaporation using a lab oven was chosen, because of its easy control and operation. Samples of $100 \mathrm{~mL}$ of waste were dried for about $16 \mathrm{~h}$, in the temperature of $110{ }^{\circ} \mathrm{C}$.

\subsection{Cementation}

The next step was the cementation of the dry waste. An important cementation parameter, to a good waste product, is the water/cement (w/c) ratio defined in Equation 1. A w/c range from 0.24 to 0.35 was used to solidify the waste.

$$
\frac{\mathrm{w}}{\mathrm{c}}=\frac{\text { water }(\mathrm{g})}{\text { cement }(\mathrm{g})}
$$

The cementation was performed by variation of the dried waste content and w/c ratio, in order to find the best formulation for the following experiment. In Table 2, the experimental proposal for this solidification is presented. Aiming to compare the cementation current process (liquid EC + cement) with new route (dried $\mathrm{EC}+$ cement), tests $1 \mathrm{~A}$ and $7 \mathrm{~A}$ were carried out using the current process.

Firstly, the water and dried waste were mixed. Sodium hydroxide $(\mathrm{NaOH})$ was used with the purpose to increase the $\mathrm{pH}$ until approximately 9. After that, the cementation could be carried out. Then Portland cement CP-V was added to the waste and they were mixed during 3 minutes, obtaining a homogenous paste. 
Some specimens were prepared by the compressive strength tests in cylindrical molds of $(5 \mathrm{~cm}$ $\mathrm{x} 10 \mathrm{~cm}$ ). After 28 days of curing time, the specimens were removed from the molds, the upper and lower surfaces were sanded to level them, and they were tested in a compression machine. The formulations employed for the cementation are present in Table 2.

The Figure 3 contains some of the steps for the cementation of the dried evaporator concentrate and the compressive strength.

Figure 3: Steps of the dried EC cementation and the compressive strength test.

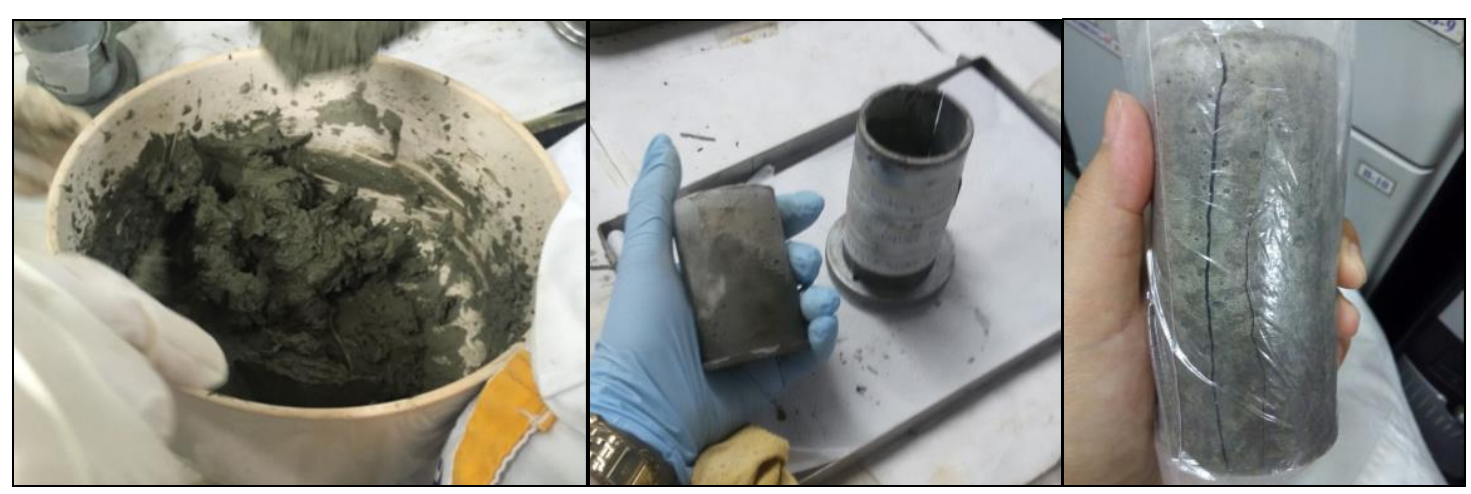

Table 2: Formulations employed to cement the dry wastes.

\begin{tabular}{|c|c|c|c|c|c|}
\hline \multirow{2}{*}{ Formulation } & \multicolumn{2}{|c|}{ Simulated Waste } & \multirow{2}{*}{$\begin{array}{c}\mathrm{NaOH} \\
(\mathrm{g})\end{array}$} & \multirow{2}{*}{ Water (g) } & \multirow{2}{*}{ w/c } \\
\hline & Dried (g) & Solution $(\mathrm{mL})$ & & & \\
\hline $\mathbf{1 A}$ & - & 147,5 & - & - & 0.35 \\
\hline $2 \mathrm{~A}$ & 18.18 & - & 5.45 & 146 & 0.35 \\
\hline $\mathbf{3 A}$ & 21.82 & - & 6.55 & 146 & 0.35 \\
\hline $4 \mathrm{~A}$ & 18.18 & - & - & 120 & 0.29 \\
\hline $\mathbf{5 A}$ & 21.82 & - & 6.55 & 112 & 0.27 \\
\hline $6 \mathbf{A}$ & 18.18 & - & 5.45 & 100 & 0.24 \\
\hline 7A & - & 128.3 & - & - & 0.30 \\
\hline $\mathbf{8 A}$ & 15.61 & - & 4.68 & 125 & 0.30 \\
\hline 9A & 15.61 & - & 4.68 & 125 & 0.30 \\
\hline 10A & 18.70 & - & 5.61 & 125 & 0.30 \\
\hline $11 \mathrm{~A}$ & 15.61 & - & 4.68 & 100 & 0.24 \\
\hline $12 \mathrm{~A}$ & 18.70 & - & 6.61 & 110 & 0.26 \\
\hline 1B & 21.82 & - & 6.55 & 112 & 0.27 \\
\hline $2 B$ & 23.73 & - & 7.12 & 112 & 0.27 \\
\hline
\end{tabular}


3B

25.00

7.50

$112 \quad 0.27$

\section{RESULTS AND DISCUSSION}

The Figure 4 contains the dried waste resulting from drying in laboratory oven and the evaporator concentrate characterization, before and after drying, is showed in Table 3.

Figure 4: Dried simulated waste.

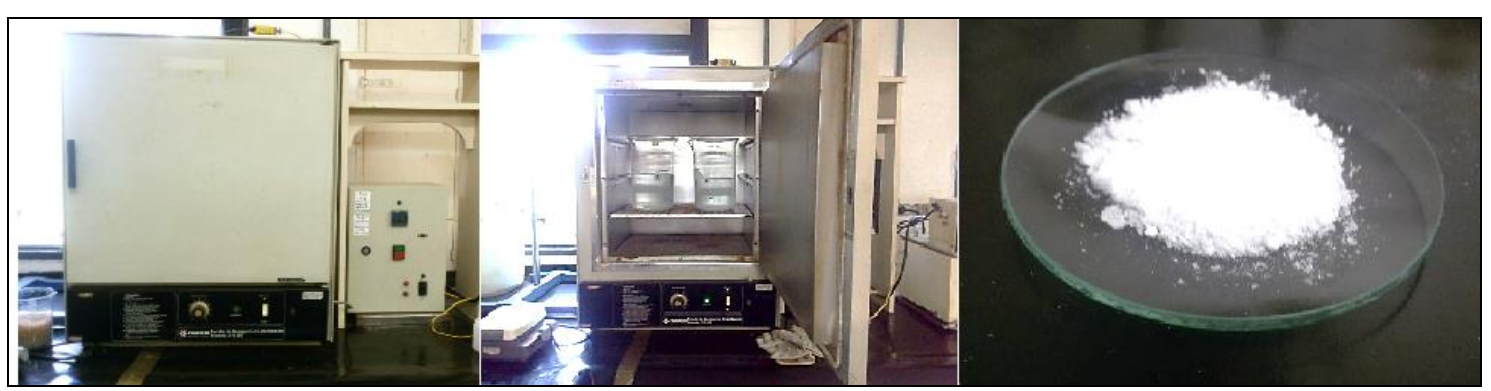

Table 3: The characteristics of simulated evaporator concentrate.

\begin{tabular}{lcc}
\hline \multicolumn{1}{c}{ Characteristics } & Waste (Solution) & Waste (Dried) \\
\hline Density $\left(\right.$ g.cm $\left.^{-3}\right)$ & 1.0 & $1.35 \pm 0.02$ \\
Boron quantity (AAS) & $0.98 \%$ & $14.8 \%$ \\
\hline
\end{tabular}

Theoretically, the simulated waste should have approximately $17 \%$ of boron. Nevertheless, the boron concentration measured in the waste by Atomic Absorption Spectrometry (AAS) was 0.98\%, i.e., the measure was performed only in the supernatant, which confirms the low boron solubility in water. The loss of boron, $14.8 \%$, probably happened because the first experiments were done in an open system in the oven lab, in other words, when the waste had been drying in the oven lab, the boron might have evaporated along with water.

The compressive strength is one of the parameters to ensure the product quality. In Table 4 are the results of this test are presented.

Table 4: Compressive strength for the cemented product. 


\begin{tabular}{c|c|c|c}
\hline \hline Formulation & CS (MPa) & Formulation & CS (MPa) \\
\hline $\mathbf{1 A}$ & 20.30 & $\mathbf{9 A}$ & 13.59 \\
\hline $\mathbf{2 A}$ & 6.00 & $\mathbf{1 0 A}$ & 10.72 \\
\hline $\mathbf{3 A}$ & 10.71 & $\mathbf{1 1 A}$ & 16.16 \\
\hline $\mathbf{4 A}$ & 4.78 & $\mathbf{1 2 A}$ & 15.29 \\
\hline $\mathbf{5 A}$ & 32.38 & $\mathbf{1 B}$ & 33.47 \\
\hline $\mathbf{6 A}$ & 23.77 & $\mathbf{2 B}$ & 31.43 \\
\hline $\mathbf{7 A}$ & 25.25 & $\mathbf{3 B}$ & 31.69 \\
\hline $\mathbf{8 A}$ & 20.16 & & \\
\hline \hline
\end{tabular}

According to Figure 4, it is observed that the cemented waste products, using the majority of the formulations, presented compressive strength value above the limit established by CNEN NN 6.09 $(\geq 10 \mathrm{MPa}$ ), including the ones containing liquid waste. The products from formulations $2 \mathrm{~A}$ and $4 \mathrm{~A}$ did not comply the minimum value of compressive strength. In the formulations $3 \mathrm{~A}$ and $5 \mathrm{~A}$, with $21.81 \mathrm{~g}$ of dried EC, the waste incorporation was $20 \%$ by weigh higher than the ones observed for liquid waste (1A and 7A).

Figure 4: Compressive strength in relation to $w / c$ ratio to $1 A-12 A$ formulations.

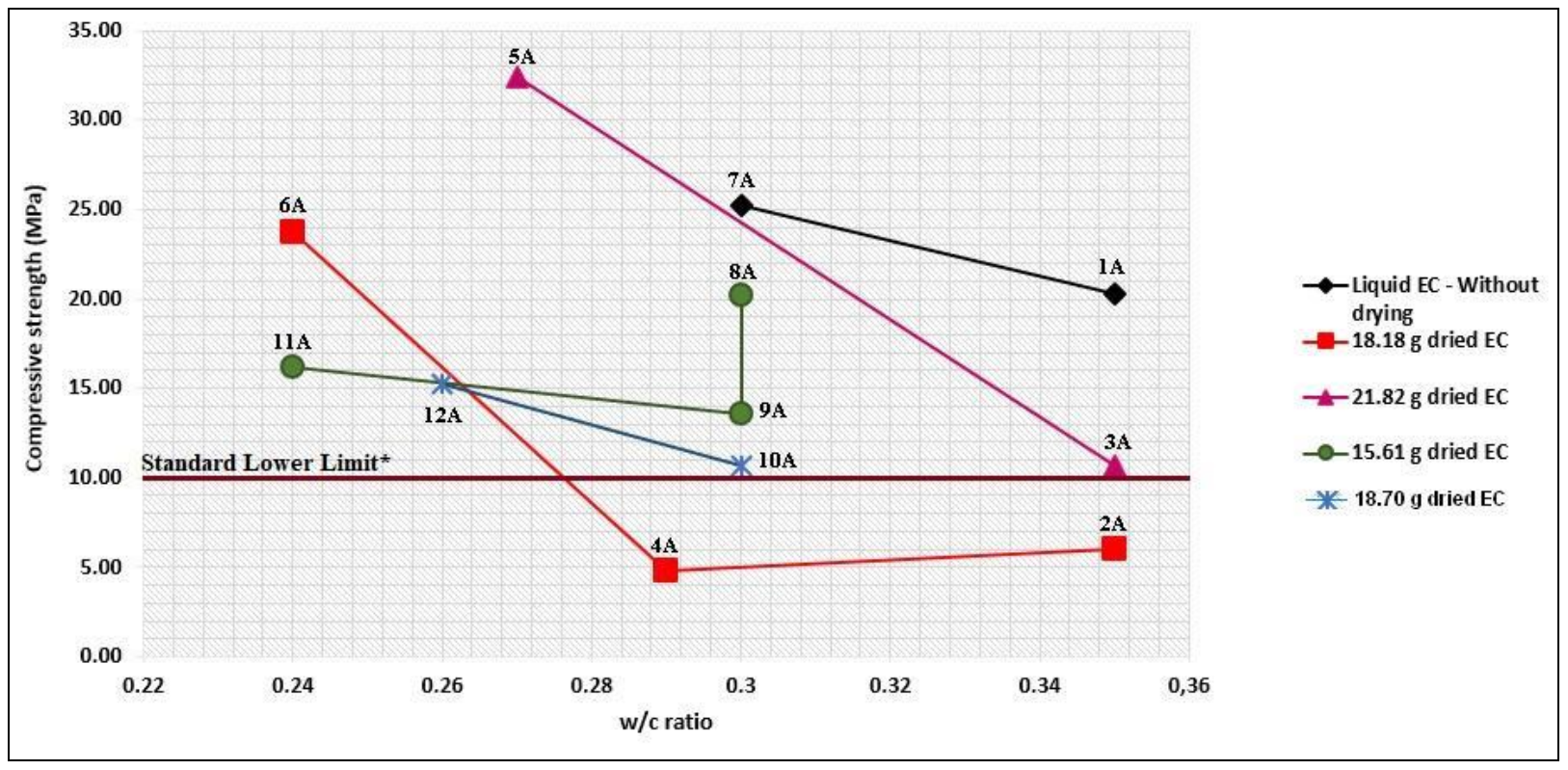

*CNEN NN 6.09 . 
As the formulation 5A presented the products with the highest compressive strength, it was selected to go on with the experiments. New formulations (1B, $2 \mathrm{~B}$ and $3 \mathrm{~B}$ ), using w/c ratio of 0.27 , were prepared. The results of compressive strength for these formulations are also presented in Table 4 , and the relationship between the compressive strength and the amount of incorporated waste (EC) is presented in the Figure 6. All compressive strength values were above $10 \mathrm{MPa}$, the standard limit [13].

Figure 6: Results of compressive strength for different incorporated evaporator concentrate amounts and $w / c$ ratio $=0.27$.

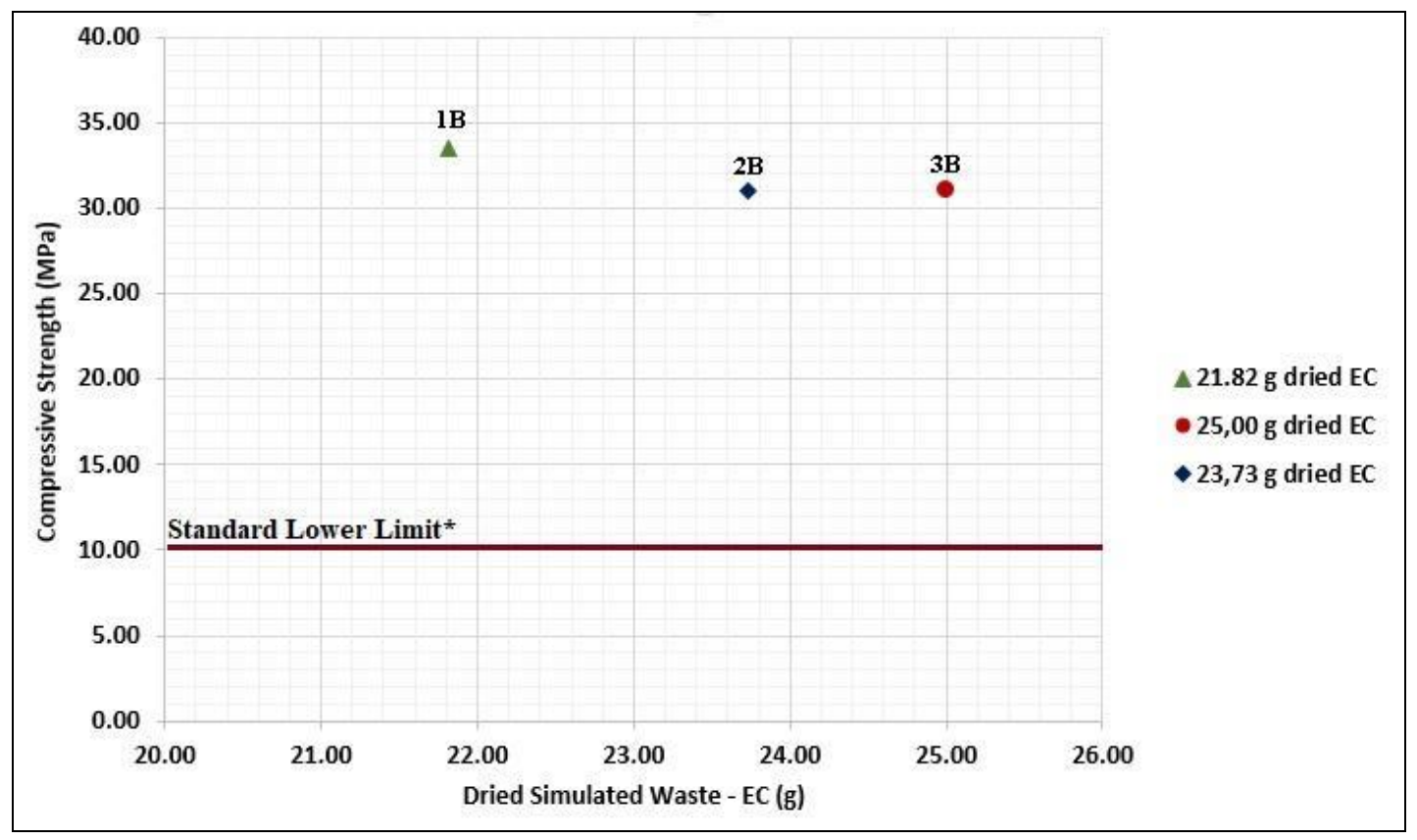

*CNEN NN 6.09 .

The highest incorporated amount of dried waste was attained using the Formulation $3 \mathrm{~B}$ with compressive strength very high (31.69 MPa), and the incorporation of the evaporator concentrate in the product was $5 \%$. Comparatively using the other formulations these values was about $3 \%$. To improve the process, tests to determine the drying time, the viscosity, the cemented product set time, the tensile strength and the leaching resistance will be performed. 


\section{CONCLUSION}

The drying process before cementation aimed to attain higher incorporations of waste in product and consequently to reduce the number the packages to be stored. From the experiments, the selected w/c ratio was 0.27 , because the cemented waste products using this value presented the higher compressive strength values, and it could be possible to incorporate more waste. Besides that, it was observed that incorporation of dried waste in relation to the current process was advantageous. The maximum incorporated waste (dried EC) was $5 \%$ by total weight in the product. Despite of the good results observed at drying in a laboratory oven, we intend to use a spray dryer in order to get a better process and to study the variables and parameters that will affect the whole process - drying/cementation.

\section{ACKNOWLEDGMENT}

We thank to Nuclear Technology Development Center - CDTN for opportunity; to Metting financial support by Foundation of the State of Minas Gerais - FAPEMIG. We thank to LABCIM (Laboratório de Cimentação), Francisco Donizete and Maria Judite for technical support.

\section{REFERENCES}

[1] ANEEL, Agência Nacional de Energia Elétrica, Atlas de Energia Elétrica do Brasil, Brasília, ANEEL, 2002. p.99-102.

[2] ELETRONUCLEAR, Panorama da Energia Nuclear no Mundo, Rio de Janeiro, 2016. 207p.

[3] QINA SUN, JIANLONG WANG, Cementation of radioactive borate liquid waste produced in pressurized water reactors, Nuclear Engineering and Design, v 240, p 3660 - 3664, 2010.

[4] QINA SUN, JUN HU, JIANLONG WANG, Optimization of composite admixtures used in cementation formula for radioactive evaporator concentrates, Progress in Nuclear Energy, v. 70, p 1-5, 2014. 
[5] INTERNATIONAL ATOMIC ENERGY AGENCY. Selection of Technical Solutions for the Management of Radioactive Waste. IAEA-TECDOC-1817. Vienna: IAEA, 2017, 114p.

[6] ABDEL RAHMAN, R. O. IBRAHIUM H. A. \& HUNG, Y., Liquid Radioactive Wastes Treatment: A Review, Water, V.3, p. 554, 2011.

[7] ELETRONUCLEAR, Relatório de Impacto Ambiental da unidade 3, Rio de Janeiro, Brazil, 2006.

Available

at:

<http://www.eletronuclear.gov.br/Portals/0/RIMAdeAngra3/03_caracterizacao.html> Last accessed: 13 Jul 2017.

[8] IAEA - INTERNATIONAL ATOMIC ENERGY AGENCY, Characterization of Radioactive Waste Forms and Packages, TRS 383, IAEA, Vienna, 1997. p.138.

[9] TOSCANO, R. A. Proposição de Processo de Tratamento de Resina e Concentrado de Evaporador Provenientes de Usinas Nucleares para o Armazenamento em Repositório de Superfície, Dissertação de Mestrado, Belo Horizonte, CDTN, 2017.

[10] TELLO, C.C.O. Avaliação de Bentonitas Nacionais como Aditivo na Cimentação de Rejeitos Radioativos, Dissertação de Mestrado, Belo Horizonte, UFMG, 1988.

[11] PERRY, R.H. \& GREEN, D.W. Perry's Chemical Engineers' Handbook, 8th ed, The McGraw-Hill, New York, 2008. Cap.12 p.26.

[12] CNEN, CNEN NN 8.01 - Gerência de Rejeitos Radioativos de Baixo e Médio Níveis de Radiação, Resolução 167/14, CNEN, Rio de Janeiro, 2014. 45p.

[13] CNEN, CNEN NN 6.09 - Critérios de Aceitação para Deposição de Rejeitos Radioativos de Baixo e Médio Níveis de Radiação. Resolução 012/02, CNEN, Rio de Janeiro, 2002. 11p.

[14] BORSSATTO, M.F.B. Desenvolvimento de Metodologia de Gerenciamento de Riscos no Projeto de Implantação do Repositório Nacional para Rejeitos Radioativos de Baixo e Médio Nível de Radiação, Dissertação de mestrado, Belo Horizonte, CDTN, 2013.

[15] TELLO, C.C.O. Efetividade das Bentonitas na Retenção de Césio em Produtos de Rejeitos Cimentados, Tese de Doutorado, Campinas, UNICAMP, 2001. 